\title{
GLOBAL PERSPECTIVES ON CANCER PAIN
}

\section{Cancer pain - progress and ongoing issues in Africa}

Olaitan Soyannwo MBBS MMed

C ancer-related pain has become a major problem worldwide. Pain can be caused by cancer, cancer treatment or by the side effects of treatment. At every stage of the cancer trajectory there is also emotional pain for both patients and the family. The dimension of these problems is worse in developing countries, especially countries in Africa, where there is a lot of ignorance about cancer, negative cultural beliefs about illness causes, poverty and lack of government policy on cancer control. Late presentation in hospitals with pain, no option of cure and poor supportive care is therefore very common (over $70 \%$ ). Denial, anxiety about the future, fear of loss of income and fear of dying contribute to late hospital visits.

The following case scenario illustrates the problem. A 56-year-old government employee presented at a general hospital where a preliminary diagnosis of rectal carcinoma was made. He was referred to a tertiary hospital, $300 \mathrm{~km}$ away. $\mathrm{He}$ reported at the referral hospital three years later with severe pain having been seeking a 'cure' at some financial expense from faith-based and traditional healers. Advanced colorectal carcinoma was confirmed with liver metastasis and ascites. He could only be offered psychosocial support, and pain and symptom control, and he died within six weeks.

The health priorities in developing countries, including African countries, as addressed in the United Nations Millennium Development Goals (MDGs), emphasize "areas that cause widespread illness and death amongst the population". Listed priorities include eradication of poverty and hunger, universal primary education, gender equality, reduction of child mortality, improvement of maternal health, combatting HIV/AIDS, malaria and other major diseases, environmental sustainability and global partnership for development (1). I believe the way forward for Africa will be to advocate actively for inclusion of cancer among the priority diseases within the MDGs and explore the area of global partnership for effective cancer control and treatment, including the multidimensional problem of cancer pain.

Currently, enough knowledge and skills on cancer pain are available in the developed world for translation into evidencebased, cost-effective and culturally appropriate interventions for Africa. The World Health Organization (WHO) (2) has also pioneered a public health strategy of palliative care to reach everyone in the population through:

- appropriate government policies;

- adequate drug availability;

- education of the public, policymakers and health professionals; and

- implementation.

Cancer pain was a target symptom and cancer the disease when the strategy was developed. With appropriate education and availability of essential drugs, adequate pain relief can be achieved in more than $75 \%$ of cancer patients using simple techniques such as opioids, nonopioid analgesics and adjuvant medications (3).
However, for many countries in Africa, availability of opioid analgesics is a major challenge for effective cancer pain treatment. The mean consumption of morphine for the African region was the lowest of all the WHO regions of the world, at $0.7 \mathrm{mg} / \mathrm{capita}$. South Africa ranked the highest at $3.4 \mathrm{mg} / \mathrm{cap}$ ita (4). Where the drugs are available, cost is a major constraint (5), as is lack of knowledge.

Efforts to improve the situation include the International Association for the Study of Pain current training activities to improve pain management in Africa and other developing countries (6). Culturally appropriate and affordable palliative care is also being promoted within Africa by the African Palliative Care Association in collaboration with several international donors (7). Palliative care emphasizes pain and symptom control, and psychosocial and spiritual support, thus ensuring the best quality of life for patients and support for families. In line with the WHO Community Health Approach to Palliative Care, Uganda has evolved a suitable model for Africa that emphasizes home care, which is mostly delivered by relatives who are supported by specially trained palliative nurse prescribers, an outpatient clinic and a day care hospice (8). Such models can be adopted to provide costeffective cancer pain relief in other African countries.

With support from the government of each country and international agencies, palliative care models could be developed through public-private partnerships, and standards improved and services upgraded to include advanced pain treatment options. The development of multidisciplinary pain clinics should also be encouraged so that local institutions would be able to include cancer pain management and research in the curriculum of their trainees.

Department of Anaesthesia, University of Ibadan College of Medicine/ University College Hospital, Ibadan, Nigeria

\section{REFERENCES}

1. United Nations Millennium Development Goals. <http://www.un.org/ millenniumgoals/> (Version current at March 23, 2009).

2. Stjernsward J, Foley KM, Ferris FD. The public health strategy for palliative care. J Pain Symptom Manage 2007;33:486-93.

3. World Health Organization. Cancer Pain Relief, 2nd edn. With a guide to opioid availability. Geneva: World Health Organization, 1996.

4. Joranson DE. Unavailability of opioid analgesics for relief of pain in Africa. <http:www.medisch.wisc.edu?painpolicy/publical/monograp/ unavailability_africa.htm $>$ (Version current at March 18, 2009).

5. De Lima L, Sweeney C, Palmer JL, Bruera E. Potent analgesics are more expensive for patients in developing countries: A comparative study. J Pain Palliat Care Pharmacother 2004;18:59-70.

6. IASP Developing Countries Project: Initiative for improving pain education. <http://www.iasp-pain.org>

7. APCA Mission. <http://www.apca.co.ug>

8. Jagwe J, Merriman A. Uganda: Delivering analgesia in rural Africa: Opioid availability and nurse prescribing. J Pain Symptom Manage 2007;33:5. 


\section{Cancer pain - progress and ongoing issues in Argentina}

\author{
Roberto Wenk MD
}

\section{HISTORICAL DEVELOPMENT}

Before 1960, severe undertreatment of cancer pain was the rule; it was described as unavoidable. Cancer prevention, diagnosis and treatment were subjects of interest, but symptom control was excluded.

The majority of cancer patients were not treated for pain at all, or were treated inadequately. Those more fortunate could receive intermittent injections of meperidine or morphine; some dying patients with uncontrolled pain could receive the 'lytic cocktail'.

Approximately in the 1960 s, cancer pain management (CPM) progressively became a duty of some anesthesiologists who performed analgesic blocks, intraspinal therapies, neurosurgical procedures, intravenous infusions, etc, as a part-time activity, with erratic results.

The anesthesiologists had a catalytic influence on CPM. After them, a growing number of health professionals became aware of the magnitude of the cancer pain issue and many of them began to provide pain relief. These professionals realized that pain is seldom the only symptom experienced by cancer patients and that they were best served with an integrated therapeutic approach. In 1990, palliative care (PC) was introduced to the medical scene and, since then, health professionals, patients and the public have slowly and progressively recognized the importance of this issue.

There was a reduction in the anesthesiologists' roles in CPM using interventional techniques, and CPM was incorporated within PC.

\section{CURRENT STATUS}

Despite the progress made in the past decades, only a small fraction of patients with cancer pain receive adequate treatment. Access to PC is inconsistent and poorly coordinated.

\section{Health system}

$\mathrm{PC}$ is not a priority in public health and has a low importance compared with preventive and curative services. Three factors can be identified:

Insufficient support: The government is still unable and/or reluctant to fulfill the demand for $\mathrm{PC}$.

- $\mathrm{PC}$ is not recognized as a discipline nationwide, although it has been recognized as a discipline in one province.

- There is no national health policy to implement PC.

- Bills, regulations and laws that promote and should guarantee nationwide $\mathrm{PC}$ access are still on paper.

Financing challenges: PC activity is difficult to finance because of inadequate compensation from the health system. Sustainability is solved with mixed approaches: charity, volunteer work, and care paid by the patient (when possible) or by health coverage (some pay for PC).

Barriers to opioid availability and accessibility: In 2006, the mean morphine and methadone consumptions were $0.66 \mathrm{mg}$ and $0.24 \mathrm{mg}$ per capita, respectively; global means were $8.74 \mathrm{mg}$ and $5.98 \mathrm{mg}$ per capita, respectively.
- There is good availability of commercial and compounds of weak and strong opioids but their high prices limit access and use.

- Although morphine and codeine should be supplied free to all patients, provision is variable to inpatients and limited to outpatients in public hospitals; this also varies by region.

- Outdated and nonscientific prescribing regulations restrict the use of opioids.

\section{HEALTH PROFESSIONALS}

\section{Teams}

The total number of identified PC teams is approximately 70 .

- Most are in large cities - those within the public health system deliver inpatient care and those in the social security system deliver home care.

- Many are interdisciplinary - a trained professional works with professionals of other disciplines according to the patients' needs.

- Only a few teams have specific inpatient facilities - there are approximately $40 \mathrm{PC}$ beds in the country.

- Home care has had limited development and day care facilities are scarce.

\section{Access}

There is limited national information about the number of patients who receive $\mathrm{PC}$, as well as clinical, organizational and economic issues of the caring process, but it can be estimated that less than $5 \%$ of patients who need $\mathrm{PC}$ receive it.

\section{Models of care}

The traditional medical model is prevalent - quality of life is replaced by excessive medical interventions that too often are futile and expensive, and sometimes in conflict with the patient's wishes.

\section{National association}

The Argentinean Association for Medicine and Palliative Care (AAMyCP) was created in 1991 and currently has approximately 250 members.

\section{Education}

- Undergraduate education for physicians and nurses is scarce.

- Graduate education is available in multiple formats classroom, bedside, workshops, seminars and e-teaching. Most are interdisciplinary.

- Opportunities for intensive training are only available in two cities.

\section{Research}

There is limited research activity with heterogeneous quality. The reasons are limited resources, minimal expertise, and lack of trained researchers and training opportunities. The number of publications per year is very low.

\section{Lack of rewards and incentives}

Payment mechanisms encourage the overuse of procedural services. It is easier and more profitable to hospitalize a patient, or start an aggressive and often futile treatment, than to provide $\mathrm{PC}$. 


\section{Patients and families}

The care of the patient with advanced cancer and his family depends on: where they live - most PC is available in large cities because it is hardly obtainable in small cities and rural areas; available resources, effective health coverage and/or money more than $50 \%$ of patients cannot pay for the services or the medication; and age - pediatric PC is limited.

\section{LOOKING FORWARD}

In Argentina, there is growing evidence that PC is useful and needed; every year, in many cities, a new team develops. However, availability is still far from an acceptable level. Legislation favours development but bureaucracy and inactivity at the public service level hinder success. Progress will be slow until the country develops a public health strategy that includes PC. A possible catalytic factor for this would be that communities 'own PC'. This must be understood as a call for social participation. Educating the community about their right to demand high-quality assistance at the end of life will require much effort, commitment and resistance to failures and deceptions.

Director, Programa Argentino de Medicina Paliativa-Fundación FEMEBA (PAMP-FF). Correspondence: Dr Roberto Wenk, Belgrano 585, 2900 San Nicolás, Argentina.

E-mail rdwenk@arnet.com.ar

\section{SOURCE MATERIAL}

1. Pain @ Policy Studies Group. Country Profiles. <http://www. painpolicy.wisc.edu/internat/countryprofiles.html> (Version current at April 12, 2009).

2. Wenk R, Bertolino M, DeLima L. Analgésicos opioides en Latinoamérica: La barrera de accesibilidad supera la de disponibilidad. Med Pal 2004;11:148-51.

3. Wenk R, DeLima L, Eisenchlas J. Palliative care research in Latin America. Results of a survey in the region. Submitted for publication.

4. Stjernswärd J, Foley KM, Ferris FD. Palliative care: The public health strategy for palliative care. J Pain Symptom Manage 2007;33:486-93.

5. Hall JJ, Taylor R. Health for all beyond 2000: The demise of the Alma-Ata Declaration and primary health care in developing countries. Global Health. <http://www.mja.com.au/public/ issues/178_01_060103/hal10723_fm.pdf> (Version current at April 12, 2009).

\section{Cancer pain - progress and ongoing issues in Australia}

\section{David C Currow MPH FRACP ${ }^{1}$, Debra S Rowett B Pharm²}

$\mathrm{T}$ here are a number of key issues that influence pain control that are country specific, irrespective of the clinical need of the population served. People with cancer in resource-rich countries differ very little around the world. What distinguishes their care is equity of access to clinicians and to the therapies that these clinicians can provide. At a health system level, three key factors stand out in determining the therapies available: the threshold of evidence required, particularly with regard to safety, efficacy and cost-effectiveness; the affordability and accessibility of that therapy; and the appropriate uptake of therapies into routine clinical practice.

The Australian health system provides universal health insurance for all citizens (Medicare) that may be augmented with private health insurance. Cancer therapies, including analgesics, are subsidized through the nationally administered Pharmaceutical Benefits Scheme. A medication (including its formulation, route of administration and specific indications) must be registered by the Therapeutic Goods Administration and recommended by the Pharmaceutical Benefits Advisory Committee, having met criteria for cost-effectiveness before it can be considered for public subsidy (1).

\section{Evidence for practice}

In a commitment to improve the evidence base for clinical practice in symptom control, the Australian government has funded a national Clinical Studies Collaborative. This Collaborative was established to generate the evidence required for consideration by regulatory authorities for registration and public subsidy in key cancer symptoms, including pain (2). Medications currently being studied are older medicines that are off patent. There is little incentive for the pharmaceutical industry to undertake the required studies for indications beyond those for which they already have marketing licences. Given the level of evidence required for registration applications, phase III, multisite, double-blind, randomized controlled trials are being conducted by the Collaborative with parallel pharmacoeconomic analyses. Given scientific equipoise despite widespread clinical use in pain, an adequately powered study of ketamine compared with placebo over five days is being conducted in people with pain that did not respond to a combination of appropriate first-line therapies, with the predominant population being people with advanced cancer (3). Ten sites are one-quarter the way through recruiting to this landmark study.

\section{Availability of opioids}

The availability of any medication is influenced by a number of factors, but cost and the country's health care system regulatory framework are important enablers. Opioids are governed at two levels in Australia - national legislation governs the manufacture, distribution and subsidy, and state and territory level legislation ensures adequate clinical oversight. Overall, the use of opioids in Australia is at the higher end per capita for a developed nation (4).

Most recently, policy has been developed that facilitates longer term use of opioids where there is a clinical need, making it possible for any medical practitioner to prescribe opioids for up to one year with input from another medical practitioner if continuation beyond 12 months is required. This shift in policy acknowledges the therapeutic need for opioids and the clinical challenges that occur if opioid-responsive pain is not treated adequately and early, while remaining vigilant for the risk of diversion of therapeutic opioids for illicit use (5).

\section{Translation into practice}

Australia has a national medicines policy with four 'pillars', one of which is to ensure quality use of medicines (6). A focus of quality use of medicines programs has been optimizing the outcomes from analgesics while minimizing the harm. For example, national campaigns funded by the Australian government, such as those conducted by the National Prescribing Service $(7,8)$, have been implemented and have reduced singledose parenteral opioids (especially pethidine) in the community. Others have addressed barriers to prescribing oral and transdermal opioids when clinically indicated for people with a 
range of pain, including cancer-related pain. Ensuring adequate clinical support as the availability and use of oral and transdermal opioids broadened in line with best available evidence (efficacy, effectiveness, lack of illicit diversion and the need to minimize the likelihood of long-term chronic pain syndromes) required specific national resources.

The continued systematic expansion of equitable access to therapies for more effective treatment of acute and chronic pain in primary care and tertiary settings has been a fundamental focus of national policy and practice improvement measures. Continued expansion of the evidence base and subsequent translation into practice through targeted, funded programs will help to ensure better control of cancer pain.

${ }^{1}$ Professor, Department of Palliative and Supportive Services, Flinders University, Bedford Park; ${ }^{2}$ Director, Drug and Therapeutics Information Service, Repatriation General Hospital, Daw Park, South Australia, Australia. Correspondence: Professor David C Currow, Southern Adelaide Palliative Services, 700 Goodwood Road, Daw Park, South Australia 5041, Australia. Telephone 61-8-8275-1871, fax 61-8-8374 4018, e-mail david.currow@rgh.sa.gov.au

DISCLAIMERS: This paper presents original work. All authors contributed to the concept and writing of this paper.

\section{REFERENCES}

1. Parliament of Australia. The Pharmaceutical Benefits Scheme an overview 2003. <http://www.aph.gov.au/library/intguide/SP/pbs. htm>.

2. Rowett D, Ravenscroft PJ, Hardy J, Currow DC. Using national health policies to improve access to palliative care medications in the community. J Pain Symptom Manage 2009;37:395-402.

3. Eccleston C, Kalso EA, Bell RF. Ketamine as an adjuvant to opioids for cancer pain. Cochrane Database of Systematic Reviews 2003, Issue 1. Art. No.: CD003351. DOI: 10.1002/14651858.CD003351.

4. Annual report of the International Narcotic Control Board, 2008. $<$ http://www.incb.org/incb/en/annual-report-2008.html $>$.

5. Basbaum AI. Spinal mechanisms of acute and persistent pain. Reg Anesth Pain Med 1999;24:59-67.

6. Commonwealth Department of Health and Ageing. The National Strategy for Quality Use of Medicines. Canberra: 2002. <http://www. health.gov.au/internet/wcms/publishing.nsf/Content/CA777524C860D FF2CA256F1800468B61/\$File/natstrateng.pdf >.

7. National Prescribing Service. Practice Review Number 35. <http:// www.nps.org.au/health_professionals/publications/prescribing_practice_ review/editions/current/prescribing_practice_review_35/analgesic_ choices_in_persistent_pain>.

8. Commonwealth Department of Health and Aged Care. The National Medicines Policy. Canberra: Publications Production Unit, 1999. $<$ www.nmp.health.gov.au/pdf/nmp2000.pdf>.

\section{Cancer pain - progress and ongoing issues in Canada}

\author{
Sharon Watanabe MD, Yoko Tarumi MD
}

$\mathrm{C}$ ancer patients in Canada receive care in a publicly funded system. Although the federal government is responsible for enforcing the standards of the Canada Health Act (public administration, comprehensiveness, universality, portability and accessibility), the 13 provincial and territorial governments exercise considerable autonomy in the delivery of health care services. Hence, cancer pain management in Canada has historically evolved from local efforts, rather than a uniform national approach.
The management of cancer pain often occurs within the context of palliative care services. While access to basic palliative care in Canada is theoretically universal, the availability of specialist palliative care is variable. Strategies to increase access to specialist palliative care include the creation of regional palliative care programs that integrate and coordinate services across the continuum of care. One example is the Edmonton Regional Palliative Care Program (1). In this model, primary palliative care is provided by family physicians and home care. Patients who are unable to remain at home until death may be admitted to hospice units. Those with complex symptom management needs may be admitted to a tertiary palliative care unit. Consulting teams provide support to attending physicians in the community, acute care hospitals and the cancer centre. Since the inception of the program in 1995, the number of cancer patients using specialist palliative care services before death has increased from $21.6 \%$ in 1992 to $82.3 \%$ in 2004 . Deaths in acute care have decreased from $78 \%$ to $41.1 \%$, with a corresponding increase in the percentage of deaths at home or in hospices (2). The cost impact to the health care system has been neutral (3). A key feature of the program is the routine application of common symptom assessment tools in all settings. For example, the Edmonton Symptom Assessment System (4), Folstein Mini Mental State Examination (5) and CAGE Questionnaire (6) are used to assess symptom severity, cognitive function and history of alcoholism, respectively. The Edmonton Classification System for Cancer Pain is used to describe pain according to mechanism, incident nature, psychological distress, addictive behaviour and cognitive function (7). Besides providing clinically relevant information, these tools facilitate communication between settings, enable common standards of practice and serve as a basis for outcome evaluation.

Pain assessment and management have been increasingly integrated into cancer care in Canada and are, in fact, mandated by national accreditation standards for cancer care facilities. Some provincial cancer agencies have developed evidence-based pain management guidelines $(8,9)$. In a quality improvement project in Ontario, all lung cancer patients attending 13 regional cancer centres completed the Edmonton Symptom Assessment System via touch-screen kiosk at each clinic visit, or via the Internet at home. Comprehensive assessment was triggered by scores exceeding predetermined cut-off values. This system was found to be feasible and associated with reductions in severe symptom scores within $72 \mathrm{~h}$ (10). Several 'fast track' palliative radiotherapy clinics have been developed across Canada to reduce wait times and the number of visits for symptomatic patients. One clinic reported a median time from referral to consultation of four days, with simulation and treatment occurring on the same day in the majority of patients (11).

Deficiencies in knowledge, attitudes and education regarding cancer pain management among Canadian physicians have been documented in multiple surveys $(12-15)$. The federally funded Educating Future Physicians in Palliative and End-ofLife Care initiative has enabled the development of national consensus-based competencies for undergraduate education of medical students, and a curriculum based on those competencies. National accreditation standards for residency programs in family medicine, medical oncology and radiation oncology 
mandate teaching in symptom management. Specialist-level training in palliative medicine may be obtained through a oneyear residency program, jointly accredited by the Royal College of Physicians and Surgeons of Canada and the College of Family Physicians of Canada. Another federally funded endeavor, the Pallium Project, has supported the continuing education of health care professionals through development of peer-reviewed resources, such as courseware and handbooks (16).

Opioids are widely available in Canada, including morphine, hydromorphone, oxycodone, fentanyl and methadone. Canada leads the World Health Organization Region of the Americas in per capita consumption of morphine and hydromorphone (17). Nonetheless, data from a palliative radiotherapy clinic in one cancer centre suggest that pain is often undermedicated (18). In some provinces, opioid prescriptions are monitored by regulatory bodies. The prescribing of methadone is limited to physicians who have been granted authorization by the federal government.

Funding for research in cancer pain in Canada is available from various public agencies. The New Emerging Team Grant in Difficult Cancer Pain, awarded by the Canadian Institutes of Health Research, is notable for enabling the focused interdisciplinary collaboration of researchers from across the country. Activities have been grouped around the themes of classification and assessment, intervention, database management, knowledge transfer and education. The project has yielded a number of publications to date (19-22).

Division of Palliative Care Medicine, Department of Oncology, University of Alberta

\section{REFERENCES}

1. Fainsinger RL, Brenneis C, Fassbender K. Edmonton, Canada: A regional model of palliative care development. J Pain Symptom Manage 2007;33:634-9.

2. Regional Palliative Care Program Annual Report: April 1, 2004 March 31, 2005 and April 1, 2005-March 31, 2006. <http://www. palliative.org > (Version current at April 13, 2009).

3. Fassbender K, Fainsinger R, Brenneis C, Brown P, Braun T, Jacobs P. Utilization and costs of the introduction of system wide palliative care in Alberta, 1993-2000. Palliat Med 2005;19:1-8.

4. Bruera E, Kuehn N, Miller MJ, Selmser P, Macmillan K. The Edmonton Symptom Assessment System (ESAS): A simple method for the assessment of palliative care patients. J Palliat Care 119;7:6-9.

5. Folstein MF, Folstein S, McHugh PR. 'Mini-mental state': A practical method for grading the cognitive state of patients for the clinician. J Psych Res 1975;12:189-98.

6. Ewing J. Detecting alcoholism: The CAGE Questionnaire. JAMA 1894:252:1905-7.

7. Fainsinger RL, Nekolaichuk CL. A 'TNM' classification system for cancer pain: The Edmonton Classification System for Cancer Pain (ECS-CP). Support Care Cancer 2008;16:547-55.

8. Broadfield L, Banerjee S, Jewers H, Pollett AJ, Simpson J. Guidelines for the management of cancer-related pain in adults. Cancer Care Nova Scotia, 2005. <http://www.cancercare.ns.ca> (Version current at April 13, 2009).

9. Cancer-related pain management: A report of evidence-base recommendations to guide practice. Cancer Care Ontario, 2008. $<$ http://www.cancercare.on.ca> (Version current at April 13, 2009).

10. Dudgeon DJ, King S, Hughes E, et al. Improving the quality of care and decreasing the morbidity of patients with lung cancer through routine symptom screening. J Clin Oncol 2008;26 (May 20 suppl; abstr 9621).

11. de Sa E, Sinclair E, Mitera G, et al. Continued success of the rapid response radiotherapy program: A review of 2004-2008. Support Care Cancer DOI 10.1007/s00520-009-0585-7.
12. MacDonald N, Findlay HP, Bruera E, Dudgeon D, Kramer J. A Canadian survey of issues in cancer pain management. J Pain Symptom Manage 1997;14:332-42.

13. Burge F, McIntyre P, Kaufman D, Cummings I, Frager G, Pollett A. Family medicine residents' knowledge and attitudes about end-of-life care. J Palliat Care 2000;16:5-12.

14. MacDonald N, Ayoub J, Farley J, Foucault C, Lesage P, Mayo N. A Quebec survey of issues in cancer pain management. J Pain Symptom Manage 2002;23:39-47.

15. Gallagher R, Hawley P, Yeomans W. A survey of cancer pain management knowledge and attitudes of British Columbian physicians. Pain Res Manage 2004;9:188-94.

16. Aherne M, Pereira JL. Learning and development dimensions of a pan-Canadian primary health care capacity-building project. Leadersh Health Serv 2008;21:229-66.

17. Pain \& Policy Studies Group. <http://www. painpolicy.wisc.edu/> (Version current at April 13, 2009).

18. Kirou-Mauro AM, Hird A, Wong J, et al. Has pain management in cancer patients with bone metastases improved? A seven-year review at an outpatient palliative radiotherapy clinic. J Pain Symptom Manage 2009;37:77-84.

19. Hagen NA, Stiles C, Nekolaichuk C, et al. The Alberta Breakthrough Pain Assessment Tool for cancer patients: A validation study using a Delphi process and patient think aloud interviews. J Pain Symptom Manage 2008;35:136-52.

20. Fainsinger RL, Fairchild A, Nekolaichuk C, Lawlor P, Lowe S, Hanson J. Is pain intensity a predictor of the complexity of cancer pain management? J Clin Oncol 2009;27:585-90.

21. Nekolaichuk C, Watanabe S, Beaumont C. The Edmonton Symptom Assessment System: A 15-year retrospective review of validation studies (1991-2006). Palliat Med 2008;22:111-22.

22. Watanabe S, Nekolaichuk C, Beaumont C, Mawani A. The Edmonton Symptom Assessment System: What do patients think? Support Care Cancer DOI: 10.1007/s00520-008-0522-1.

\section{Cancer pain - progress and ongoing issues in Europe}

\section{Stein Kaasa ${ }^{1}$, Sebastiano Mercadante ${ }^{2}$, Augusto Caraceni ${ }^{3}$}

$\prod$ he prevalence rate of pain in cancer patient cohorts varies from $10 \%$ to $90 \%$, with great differences in what is described as severe pain, significant pain or undertreated pain (1-3). The knowledge about cancer breakthrough pain suffers from the same variability (10\% to $85 \%)(4-7)$.

The contrast between the key outcomes in cancer palliative care and cancer care in general are considerable. When comparing data between studies on cancer pain, large variations are observed in the classification of the palliative care cohort, how cancer pain cohorts are classified, how pain is measured in the clinic, health surveys and epidemiological studies, and major variations in the treatment of pain within and among institutions.

\section{Some reasons for the observations}

The development of palliative care in the 1960s and 1970s in Europe happened to a large extent outside academic institutions, with a major focus on direct patient care and service development, and less focus on the development of an academic systematic approach toward diagnosis and treatment (8).

Pain is a subjective symptom that needs a different methodology than a cancer diagnosis to be diagnosed and understood at individual and group patient levels. The common definition of pain by the International Association for the Study of Pain (IASP) was published first in 1979 (9). This 'recent' arrival of an explicit definition may explain the lack of any international consensus on how to assess and classify pain. 
The oncologists were pragmatic and decided to develop a 'simple' TNM system, as well as 'simple systems' for understanding the histology of the disease. Looking back at these staging systems, the systems today are much more advanced. The TNM system and early systems for classifying lymphoma and other tumours have been a major contribution to improving the treatment and understanding of cancer disease.

Another argument often put forward is the 'resource argument' - "We do not have the economical backbone to conduct high-quality research". However, if all existing resources were put into collaborative actions, more substantial achievements may have been obtained (10). Therefore, the European Association for Palliative Care Research Network (EAPC RN) will coordinate actions across Europe to conduct research projects that secure sufficient sampling, with the end result of developing evidence-based guidelines (EBGs). This strategy may be considered a natural development of the expert committee guidelines (treatment of pain, cachexia, depression, constipation, etc) (11), the pan-European survey on patient treatment (12) and service delivery (13).

Recently, the EAPC and others have evaluated the present status of palliative care research (8):

- Too many small research groups scattered throughout Europe;

- Few of them are based within a university;

- Too few meeting points for discussion and exchange of knowledge;

- Lack of long-term funding;

- The EAPC RN has limited funding, thus the basic structure to plan and conduct pan-European studies is limited; and

- The EAPC RN is not a legal entity that can apply for European Union (EU) or national funding.

\section{A plan for future development}

Through the EU-funded European Palliative Care Research Collaborative (EPCRC), which was funded in 2006 (EU's sixth framework) (14), as well as other EU-funded and several other international and national research projects, a new development of collaborative actions will be undertaken by the EAPC RN to establish a European centre (15).

Some three- to five-year goals have been identified, as follows:

- Coordinate actions between groups and individual researchers across Europe and from the United States, Canada and Australia;

- Plan and conduct international multicentre studies;

- Promote palliative care research in Europe with the aim to improve research funding;

- Initiate and develop EBGs and perform updates of treatment guidelines when appropriate;

- Establish an international $\mathrm{PhD}$ program for teaching young investigators; and

- Develop consensus-based systems for assessment and classification of cancer pain.

\section{Evidence-based cancer pain treatment}

Evidence-based practice (EBP) is used through the implementation of EBGs into daily clinical practice. The quality of EBP depends on several factors; among these are the quality of the recommendations in the EBG, the validity of the studies conducted that guide each recommendation, and a common understanding of the guided treatment and relevant patient cohort. EBGs are only one of several factors that guide each individual doctor. Other strong factors include the doctors' own preferences and experiences. However, when the validity of guidelines improves and a common understanding of the need for EBP is reached, one may expect improved cancer pain control.

In the latest EAPC recommendations on morphine and alternative opioids, the majority of the recommendations were at level C (16). To apply clinical studies into practice, a clear description of the cohort of patients in the studies and a similar understanding about classification of each individual patient in practice are needed, as well as a common language or system for the assessment of pain and other key symptoms. Methodology has been suggested by the EPCRC on how to systematically develop assessment and classification systems (17).

Despite the recognition of the need for common assessment tools for cancer pain, there is a continuous flow of new instruments (18). This development seems to be driven by specific research interests rather through a consensus-based process between researchers, institutions and countries (19). A similar situation is also observed for cancer pain classification. However, fewer systems exist in the area of classification compared with assessment. In a recent systematic review, six classification systems for cancer pain were identified (20). Based on this review, the EPCRC recommended taking advantage of the long-term development of the Edmonton Classification System for Cancer Pain $(21,22)$ and further developing it into an international classification system.

As a first step in this process of standardizing cancer pain classification and assessment, an international meeting will bring together international experts on cancer pain assessment and classification, representatives from professional associations interested in oncology (European Society for Medical Oncology, American Society of Clinical Oncology) pain (IASP) and palliative care (EAPC), and advisors from the European Medicines Agency and the United States Food and Drug Administration, to discuss and enforce a position paper on the need to standardize the reporting of cancer pain characteristics at the international level.

1Pain and Palliation Research Group, Department of Cancer Research
and Molecular Medicine, Faculty of Medicine, NTNU; Palliative
Medicine Unit, Department of Oncology, Trondheim University
Hospital, Trondheim, Norway; Istituto Nazionale Dei Tumori,
Milano, Italy; ${ }^{2}$ Intensive Care Unit Eु Pain Relief and Palliative
Care Unit, La Maddalena Cancer Center, Palermo and University
of Palermo, Intensive Care and Emergency, Palliative Medicine
Teaching, Palermo, Italy; ${ }^{3}$ Palliative Care (Pain Therapy -
Rehabilitation) Fondazione IRCCS, National Cancer Institute
of Milan, Italy. Correspondence: Stein Kaasa.
E-mail stein.kaasa@ntnu.no

\section{REFERENCES}

1. Hearn J, Higginson I. Cancer pain epidemiology: A systematic review. In: Bruera E, Portenoy RK, eds. Cancer Pain Assessment and Management. Cambridge: Cambridge University Press, 2003:19-37.

2. Deandrea S, Montanari M, Moja L, Apolone G. Prevalence of undertreatment in cancer pain. A review of published literature.Ann Oncol 2008;19:1985-91. 
3. Breivik H, Cherny N, Collett B, et al. Cancer-related pain: A pan-European survey of prevalence, treatment, and patient attitudes. Ann Oncol 2009. (In press).

4. Apolone G, Corli O, Caraceni A, et al; Cancer Pain Outcome Research Study Group (CPOR SG) Investigators. Pattern and quality of care of cancer pain management. Results from the Cancer Pain Outcome Research Study Group. Br J Cancer 2009;100:1566-74.

5. Caraceni A, Martini C, Zecca E, et al. Working Group of an IASP Task Force on Cancer Pain. Breakthrough pain characteristics and syndromes in patients with cancer pain. An international survey. Palliat Med 2004;18:177-83.

6. Svendsen KB, Andersen S, Arnason S, et al. Breakthrough pain in malignant and non-malignant diseases: A review of prevalence, characteristics and mechanisms. Eur J Pain 2005;9:195-206.

7. Mercadante S, Radbruch L, Caraceni A, et al. Steering Committee of the European Association for Palliative Care (EAPC) Research Network. Episodic (breakthrough) pain: Consensus conference of an expert working group of the European Association for Palliative Care. Cancer 2002;94:832-9.

8. Kaasa S, Radbruch L. Palliative care research - priorities and the way forward. Eur J Cancer Clin Oncol 2008;44:1175-9.

9. Caraceni A, Portenoy RK. An international survey of cancer pain characteristics and syndromes. IASP Task Force on Cancer Pain. International Association for the Study of Pain. Pain 1999;82:263-74.

10. Kaasa S, Hjermstad MJ, Loge JH. Methodological and structural challenges in palliative care research: How have we fared in the last decades? Palliat Med 2006;20:727-34.

11. <www.eapcnet.org>.

12. Klepstad P, Kaasa S, Cherny N, Hanks G, de Conno F; Research Steering Committee of the EAPC. Pain and pain treatments in European palliative care units. A cross sectional survey from the European Association for Palliative Care Research Network. Palliat Med 2005;19:477-84.

13. Kaasa S, Torvik K, Cherney N, Hanks G, de Conno F. Patient demographics and centre description in European palliative care units. A cross sectional survey of the European Association for Palliative Care (EAPC) Research Network. Palliat Med 2007;21:15-22.

14. <www.epcrc.org>.

15. <www.ntnu.no/palliativeresearch>

16. Hanks GW, de Conno F, Cherny N, et al. Morphine and alternative opioids in cancer pain: The EAPC recommendations. Br J Cancer 2001;84:587-93.

17. Kaasa S, Loge JH, Fayers P, et al. Symptom assessment in palliative care: A need for international collaboration. J Clin Oncol 2008;26:3867-73.

18. Hølen JC, Hjermstad MJ, Loge JH, et al. Pain assessment tools: Is the content appropriate for use in palliative care? J Pain Symptom Manage 2006;32:567-80.

19. Hjermstad M, Gibbins J, Haugen D, Caraceni A, Loge J, Kaasa S. Pain assessment tools in palliative care: An urgent need for consensus. Palliat Med 2008;22:895-903.

20. Knudsen A, Aass N, Fainsinger R, et al. Classification of pain in cancer patients - a systematic literature review. Palliat Med 2009;23:295-308.

21. Fainsinger RL, Nekolaichuk CL. A 'TNM' classification system for cancer pain: The Edmonton Classification System for Cancer Pain (ECS-CP). Support Care Cancer 2008;16:547-55.

22. Fainsinger R, Fairchild A, Nekolaichuk C, et al. Is pain intensity a predictor of the complexity of cancer pain management? J Clin Oncol 2009;27:585-90.

\section{Cancer pain: Progress and ongoing issues in Ireland}

\author{
Carol Stone MSc MRCP(UK) ${ }^{1}$, \\ Peter G Lawlor MMedSc FRCPI CCFP(C) ${ }^{2}$
}

A lthough there is a paucity of population and institutional audit data on the prevalence of cancer pain and the effectiveness of management in Ireland, clinical experience and preliminary analysis of a recent international multicentre study on the use of the Edmonton Classification System for Cancer Pain (unpublished data) would suggest that indices for both are broadly similar to those of other developed countries. While cancer pain is managed at multiple levels, both oncology and primary care services are supported by specialist input from palliative care and, to a lesser degree, from the chronic pain or anesthesia-based services. Access to these specialist support services is generally good, despite some patchy geographical deficiencies. Clinical experience would suggest that the timing of palliative care involvement is unfortunately often late.

A traditionally strong Irish hospice movement provided a foundation for the development of regionalized palliative care services over the past 15 years. A national advisory committee report on palliative care in 2001 received international acclaim for its clarity and recommendations for future development (1). Unfortunately, despite some exceptions, the resource allocation for palliative care services delivery still falls well short of the recommended minimum requirements in the 2001 report. Consequently, the excessive workload volume experienced by many services means that comprehensive and effective cancer pain management is continually at risk of compromise. This may, in part, explain the very limited use of systematic cancer pain assessment tools and the consequent lack of audit data at both institutional and national levels. Furthermore, there has been a traditional reluctance to 'measure' in the hospice setting, in which there has been a somewhat naïve reliance on patient and family satisfaction surveys as the sole index of the quality of cancer pain and symptom control.

Although death rates for cancer have generally decreased in Ireland, the demographic shift to a higher proportion of elderly people in the Irish population will entail an increase in the actual numbers of those with advanced cancer and cancerrelated deaths (2). The presence of multiple comorbidities in these patients will create further challenges in cancer pain assessment and management, especially in the context of cognitive impairment. The projected increase in the number of patients with cancer pain heralds the need for an expansion in resource allocation for existing palliative care services to address their increasing service delivery and educational needs.

Access to strong opioids in Ireland is comparatively good, including newer formulations such as buccal or oral dispersible formulations of fentanyl. The promotion of newer formulations is likely boosted by the large presence of many multinational pharmaceutical companies in Ireland. However, we postulate that there is little gain in having good access to strong opioids and their newer formulations if cancer pain is not assessed in a systematic or formal way. Poor assessment practices can lead to underuse and poor pain control, or misuse of opioids and the development of side effects (3). Public misconceptions regarding opioids and their side effects are probably still quite prevalent in Ireland (4). Collectively, these knowledge gaps and attitudinal deficits highlight the need for greater public and physician education regarding cancer pain management.

Palliative medicine became a recognized specialty in 1995 in Ireland, and the number of physician consultants has increased substantially since then. However, this progress contrasts starkly with the lack of development of academic palliative medicine. As a consequence, engagement in cancer pain 
research, especially randomized controlled trial involvement, has been limited and sporadic. From an educational perspective, there is a great need to establish a formal undergraduate training curriculum in palliative medicine and to promote cancer pain education among undergraduates. A similar need exists in most of the postgraduate specialty training programs, with the exception of general practice and palliative medicine.

In conclusion, the establishment of specialist palliative care services represents a significant advance in the management of cancer pain in Ireland. However, significant academic and clinical gaps exist, including the lack of systematic cancer pain assessment and the consequent failure to generate quality audit data; health care professionals' knowledge deficits regarding cancer pain; lack of collaborative engagement in research studies; and insufficiency in resource allocation, which precludes the equitable development of specialist cancer pain management services - most notably in palliative care. These gaps need to be addressed, especially in view of the projected national demographic changes and the ensuing increase in the number of patients with cancer pain.

${ }^{1}$ Health Research Board and Irish Hospice Foundation Research Fellow, Our Lady's Hospice, Dublin, Ireland; 'Consultant in Palliative Medicine, Our Lady's Hospice and St James's Hospital, Dublin, Ireland. Adjunct Associate Professor, Division of Palliative Care Medicine, Department of Oncology, University of Alberta, Edmonton, Alberta

\section{REFERENCES}

1. Report of the National Advisory Committee on Palliative Care, Department of Health and Children, Ireland 2001. <http://www.dohc. ie/publications/national_advisory_committee_on_palliative_care. html> (Version current at March 28, 2009).

2. National Cancer Registry of Ireland data. $<$ http://www.ncri.ie/news/ news.shtml> (Version current at March 28, 2009).

3. O'Leary N, Stone C, Lawlor PG. Multidimensional assessment: Pain and palliative care. In: Bruera ED, Portenoy RK, eds. Cancer Pain Assessment and Management. New York: Cambridge University Press, 2009. (In press).

4. Lawlor PG. Realities of Hospice Care. Letter to Irish Times, published May 23, 2009.

\section{Cancer pain - progress and ongoing issues in Israel}

\section{Nathan Cherny MBBS FRACP FRCP}

$\mathrm{T}$ he management of pain for cancer patients takes place in numerous settings - oncology centres, day hospitals, pain clinics, general practice and home care services. National guidelines on the management of cancer pain have existed since 1998; they are frequently updated (most recently in 2009) and have been widely disseminated at all levels of practice. Principles of cancer pain management are incorporated into the training of cancer specialists and family doctors. They are generally taught to nursing undergraduates and postgraduates. The level of training of medical students, surgical trainees and internal medicine trainees is not well regulated and is variable in quality.

Although there is a growing cadre of physicians working at the specialist level in palliative medicine in Israel, palliative medicine is not yet recognized as a medical specialty. This issue is under discussion with the accreditation committee of the Israel Medical Association.

\section{Cancer pain services in oncology centres}

Five of Israel's 10 oncology services provide expert cancer pain services delivered by palliative medicine clinicians, interested pain physicians or oncologists with a subspecialty interest. Inadequately relieved pain is a recognized indication for priority admission in most, but not all, cancer services. There are no hospital accreditation standards regulating the assessment and documentation of pain. Consequently, few hospitals incorporate it as a fifth vital sign and, indeed, the routine assessment of pain is haphazard.

\section{Cancer pain care in the community}

The Israeli Palliative Care Association has an active membership of almost 1000 drawn from a wide range of services across the country. The quality and extent of palliative care services that must be provided to patients is not yet regulated by the Ministry of Health, but this is being actively addressed. The extent and quality of home-based palliative care varies greatly between different regions of the country. In some urban regions it is very good and readily available; in others, services may be less expert and less available. Some outstanding services provide high-level palliative care to some of the patients living in remote areas. When needed, home patient-controlled analgesia is widely available and logistically well supported.

\section{Opioid availability and accessibility}

Overall, opioid availability and accessibility for cancer patients is good. A wide range of opioids is available for the management of moderate and strong cancer pain. Morphine, oxycodone and transdermal fentanyl are widely used. There is less use of parenteral hydromorphone and oral methadone, although both are available. Transmucosal fentanyl is available to patients who do not have adequate relief with oral immediaterelease formulations or in situations in which oral medication is contraindicated. For cancer patients, medications covered in the nondiscretionary basket of services, which includes all opioids, are dispensed at no cost.

Prescriptions do not require any special forms and need not be written in duplicate or triplicate. They must include personal details of the patient, including an identification number and address, and the prescription must be written both in numbers and in longhand. The prescription must be signed and stamped with the physician's license number and must have a contact telephone number for clarification or verification. If a patient presents with a prescription that has a technical error, pharmacists have little or no discretion to honour or correct the prescription and the patient must return with a fully valid prescription. Prescriptions are valid for a 30-day supply of medication. Most opioids are widely available in community pharmacies and patients need not go to special pharmacies. Some health maintenance organizations limit the dispensing of opioids to central or regional pharmacies. This sometimes causes substantial inconvenience to patients who may need to travel some distance to the pharmacy or wait in a busy hub. The regulations regarding opioid prescription and dispensing make no provision for emergency physician prescriptions by telephone or fax, or emergency prescription by nurses or pharmacists. 
Other modalities of care

Adjuvant analgesics: A wide range of adjuvant analgesics is available. Expensive agents such as pregabalin are available only after trials of less expensive options.

Radiotherapy: There is a great appreciation of the role of radiotherapy in cancer pain treatment. Patients generally have rapid access to high-quality services.

Invasive techniques: Israel has a very well-developed network of clinicians with expertise in invasive techniques. Radiofrequency with guided imaging is widely available. The application of approaches involving spinal infusions is limited by the availability of home care services skilled in the ongoing management of patients with spinal infusion devices.

Psychological services: In some centres, excellent psychological services are developed to assist in the care of patients with pain.

\section{Patients with difficult pain problems}

Reference centres with a high level of expertise exist in all regions of the country. Patients may be referred for expert evaluation and, if need be, inpatient stabilization.

In cases of truly refractory pain in patients at the end of life, there are no regulatory barriers to the use of palliative sedation. Hospitals and home care services are encouraged to develop procedural guidelines and some have already done so.

Norman Levan Chair of Humanistic Medicine, Associate Professor of Medicine (BGU), Director, Cancer Pain and Palliative Medicine Service, Department of Medical Oncology, Shaare Zedek Medical Center, Jerusalem, Israel. Correspondence: Nathan Cherny, Department of Medical Oncology, Shaare Zedek Medical Center, Jerusalem, Israel 91031. Telephone 0508-685780,

fax 972-2-6666731, e-mail chernyn@netvision.net.il

\section{Cancer pain - progress and ongoing issues in Japan}

\author{
Yoko Tarumi MD ${ }^{1,2}$, Tatsuya Morita $\mathrm{MD}^{3}$, \\ Sharon Watanabe $\mathrm{MD}^{1}$
}

$\mathrm{C}$ ancer has been a leading cause of death in Japan since 1981, accounting for $30.4 \%$ of total deaths in 2006 (1). A systematic approach for treatment of cancer pain and development of a health care system for specialized palliative care services has been progressing rapidly since 1990. The Cancer Control Act was established in 2006 to promote cancer prevention and early detection, disseminate quality palliative care, and promote cancer research (2).

Palliative care units (PCUs) provide care for $6 \%$ of all cancer deaths, whereas palliative care teams (PCTs) have been providing inpatient consultation services since 2002 in general wards, in which $91 \%$ of cancer deaths occur (3). Formerly, only patients in the terminal stage of cancer were approved for admission to PCUs; however, the criteria were revised in 2007 to include all patients with a cancer diagnosis with a considerable level of suffering. This was based on a nationwide survey, in which onehalf of patients and families reported that referral to a PCU occurred too late. Eighty-five per cent of patients experienced distressing symptoms before admission to a PCU $(4,5)$. Currently, all 353 regional cancer centres are obliged to establish PCTs, and further administrative data will be reported within the next several years (6). PCTs typically consist of physicians, nurses certified in oncology, palliative care or pain, psychiatrists, medical or radiation oncologists, anesthesiologists and pharmacists; social workers are not mandatory. The first-year audit of PCTs in one of the acute care hospitals revealed marked effectiveness in management of severe pain within one week of intervention. The most common interventions implemented were nonsteroidal anti-inflammatory drugs, opioid agonists, corticosteroids and antiemetics. A small number of patients underwent nerve blocks performed by anesthesiologists (7).

There have been a number of specialized certificate courses for comprehensive nursing care, including oncology, palliative care and pain management; however, no established and accredited residency or fellowship training programs in palliative care are available yet. Undergraduate educational programs vary throughout the 80 medical schools.

\section{CHARACTERISTIC FEATURES IN CANCER PAIN MANAGEMENT IN JAPAN}

Strategic approach in cancer pain management - clinical practice guidelines

The approach for cancer pain control has been one of the priorities throughout the development of palliative care. A survey conducted in major cancer centres in 1986 revealed that only $38 \%$ of pain was controlled, which marginally improved to $57 \%$ in $1998(8,9)$. Evidence-based guidelines for cancer pain management were established as a part of the Japanese Palliative Medicine project in 1999, which were further tested on 314 consecutive cancer patients admitted to 37 national hospitals. The postguidelines implementation group showed significantly more achievement of freedom from pain in two weeks compared with the preguidelines treatment group (14.7\% versus $8.8 \%)$. Significantly fewer adverse reactions, especially constipation and drowsiness, were found in the postguidelines group (10). The guidelines are currently under revision to include new evidence and new pharmacological options, and will appear at the end of 2010.

\section{Availability of opioids}

As of March 2009, Japan limits the availability of types of opioid agonists in cancer pain control to morphine, fentanyl, codeine, dihydrocodone and oxycodone (which only became available in 2005). Hydromorphone and methadone (which may be advantageous due to its higher analgesic potency, especially in patients requiring higher doses of opioid agonists) are not available. Although opioid consumption per capita has been increasing dramatically since the 1990s, the average consumption per capita has not reached the world average. In 2006, compared with Canada, mean morphine consumption per capita was $3.5 \mathrm{mg}$ versus $65 \mathrm{mg}$; mean oxycodone consumption per capita was $1.9 \mathrm{mg}$ versus $115 \mathrm{mg}$. Canadian figures include opioid agonists prescribed for noncancer pain (11).

The role of neural blocks and adjuvant analgesics in difficult pain syndromes

A multicentre audit survey was performed and a total of 162 interventions in 136 consecutive patients (3.8\% of all patients) were examined to clarify the frequency of neural blockade in certified PCUs and PCTs, determine the efficacy of 
interventions, and explore the predictors of successful and unsuccessful intervention. A significantly higher frequency of neural blocks occurred when the leading physician's specialty was anesthesiology. Pain intensity and opioid consumption were significantly lower in the neural block group within one week of the procedures. No improvement was seen in the Communication Capacity Scale, occurrence of delirium or performance status. Epidural nerve block, neurolytic sympathetic nerve block and intrathecal nerve block with phenol were the three most common procedures (12). Active participation of anesthesiologists in palliative care and relatively limited availability of types of opioid agonists may have contributed to the relatively high frequency of neural blocks and use of adjuvant analgesics. An example of the latter is the use of ketamine for difficult pain syndromes - such as neuropathic pain, incident pain or rapidly developing opioid tolerance that fail to respond to available opioid agonists.

${ }^{1}$ Division of Palliative Care Medicine, Department of Oncology, University of Alberta; ${ }^{2}$ Director, Palliative Care Program, Royal Alexandra Hospital, Edmonton, Alberta; ${ }^{3}$ Department of Palliative and Supportive Care, Palliative Care Team and Seirei Hospice, Seirei Mikatagahara General Hospital, Hamamatsu, Shizuoka, Japan. Correspondence: Dr Yoko Tarumi, Director, Department of Symptom Control and Palliative Care, Cross Cancer Institute, Director, Palliative Care Program, Royal Alexandra Hospital, Edmonton, Alberta. Telephone 780-735-4038, fax 780-735-5880,

e-mail Yoko.Tarumi@capitalhealth.ca

\section{REFERENCES}

1. <http://ganjoho.ncc.go.jp/public/statistics/backnumber/ odjrh3000000vdf1-att/fig10.pdf>.

2. Morita T, Miyashita M, Tsuneto S, Shima Y. Palliative care in Japan: Shifting from the stage of disease to the intensity of suffering. J Pain Symptom Manage 2008;36:6.

3. Statistics and Information Department, Minister's Secretariat, Ministry of Health, Labour and Welfare: Vital statistics of Japan 2006 [Japanese], Tokyo: 2007.

4. Morita T, Akechi T, Ikenaga M, et al. Late referrals to specialized palliative care service in Japan. J Clin Oncol 2005;23:2637-44.

5. Yamagishi A, Morita T, Miyashita M, et al. Palliative care in Japan: Current status and a nationwide challenge to improve palliative care by the Cancer Control Act and the Outreach Palliative Care Trial of Integrated Regional Model (OPTIM) study. Am J Hosp Palliat Care 2008;25:412-8.

6. Morita T, Miyashita M, Tsuneto S, Shima Y. Palliative care in Japan: Shifting from the stage of disease to the intensity of suffering. J Pain Symptom Manage 2008;36:e6-7.

7. Morita T, Fujimoto K, Tei Y. Palliative care team: The first year audit in Japan. J Pain Symptom Manage 2005;29:458-6.

8. Hiraga $K$. The recent status of the management of cancer pain. Pain Clin 1999;20:479-83.

9. Hiraga K, Mizuguchi T, Takeda F. The incidence of cancer pain and improvement of pain management in Japan. Postgrad Med J 1991;67:S14-25.

10. Fukui T, Takahashi O, Rahman M, et al. Clinical effectiveness of evidence-based guidelines for pain management of terminal cancer patients in Japan. JMAJ 2005;48:216-3.

11. International Narcotics Control Board. United Nations population data. Pain \& Policy Studies Group, University of Wisconsin/WHO Collaborating Center, 2008.

12. Tei Y, Morita T, Nakano T, et al. Treatment efficacy of neural blockade in specialized palliative care services in Japan: A multicentre audit study. J Pain Symptom Manage 2008;36:461-7.

\section{Cancer pain - progress and ongoing issues in New Zealand}

\author{
Dr WJ Landman ${ }^{1}$, Dr BA Foggo ${ }^{2}$
}

$T$ he health care system of New Zealand is predominantly a National Health Care system, funded by the government, with some elements of private health care. Total health care spending is $9.3 \%$ of the gross domestic product, of which the state funds $78 \%$. The average life expectancy is 79.9 years (Organisation for Economic Co-operation and Development statistical data). Despite being a small country, it has significant diversity in the health care environment, with a geographical mix of metropolitan and rural areas, and is multiethnic, particularly in the metropolitan areas. New Zealand has a national Palliative Care Strategy, first released in 2001, that has clear goals of providing services for all people who are dying and could benefit from palliative care. It has nine strategies that it will implement over a five- to 10 -year period to achieve this (1). These include education of health care professionals, as well as raising community awareness of palliative care services. New Zealand also has a Cancer Control Strategy, which has a Palliative Care Working Party subgroup.

In New Zealand, cancer pain in advanced cancer is mainly managed by palliative care services in hospitals and hospices. Hospital palliative care teams are dependent on general practice and hospices to continue care and review pain and symptoms at home. Hospices are community organizations, mainly based on the St Christopher's Hospice model (London, United Kingdom). St Christopher's Hospice was founded by Dame Cicely Saunders, who first described the concept of total pain, which is comprised of physical, psychological, social and spiritual dimensions (2). Despite the clear direction from the Crown, through both the Maori Health Strategy and the Palliative Care Strategy (1,3), the challenge remains to deliver a service that reflects the demography and actual needs of local communities. In Auckland, this is reflected in the variable uptake of hospice services by different ethnic groups.

TABLE 1

Referrals to Mercy Hospice Auckland and ethnic mix of Auckland District Health Board (DHB) and New Zealand populations

\begin{tabular}{lccc}
\hline & $\begin{array}{c}\text { Hospice } \\
\text { referral, \% }\end{array}$ & $\begin{array}{c}\text { Auckland } \\
\text { DHB, \% }\end{array}$ & New Zealand, \% \\
\hline European & 74 & 66 & 80 \\
Maori & 4 & 8 & 15 \\
Pacific peoples & 9 & 13 & 7 \\
Asian peoples & 8 & 19 & 7 \\
Other nations & 3 & 2 & 0.5 \\
\hline
\end{tabular}

Hospice services (and therefore specialist pain services) are not adequately reaching three major population groups, namely the Maori, Pacific and Asian peoples. Of these, the former two have attitudes and cultural expectations aligned to the traditional hospice model (holistic care, family focus, spiritual practice and desire to be cared for at home) whereas the Asian people have expectations of increasing intensity of care, often in an institutional setting. Attitudes toward use of opioids as analgesics vary among ethnic and cultural groups. Opioids tend to be less acceptable in traditional cultures, with 
a greater focus on traditional therapies (herbal therapies and massage).

There has been an increase in both the access to and availability of private (personal- or insurer-funded) oncological care in recent years, especially with development of new diagnostic and therapeutic modalities and drugs, which are not funded by the government. As a consequence of better oncological therapies, survival statistics have improved, with patients living with cancer (and therefore cancer pain) for longer than before. This has both a resource implication (human and financial), as well as increased complexity. Cancer pain prevalence rises as cancer becomes more advanced, up to $70 \%$ to $80 \%(4-6)$.

In cancer pain, the area of breakthrough pain (BTP) remains a challenge (7) in which inadequacy of assessment and management of BTP leads to decreased quality of life, with increases in anxiety and depression (8), as well as an increase in health care burden $(9,10)$. Portenoy's management of BTP (11) involved the following: consider adjuvants to treat underlying cause, optimize baseline analgesia, and use specific analgesics to match the temporal nature of the pain.

PHARMAC is the Ministry of Health agency charged with the responsibility of funding pharmaceuticals in New Zealand. It has an analgesic subcommittee that makes recommendations to the funder based on the level of evidence for efficacy, costeffectiveness and priority. As a result of this structure, as well as the small marketplace, New Zealand tends to have a lag phase in the arrival of new therapies. In New Zealand, we have the following opioids and adjuvant analgesics available and funded by the government:

\section{Opioids}

Morphine, methadone, oxycodone and fentanyl are available; the latter requires a special authority application and is only available as a transdermal patch or for parenteral use. Hydromorphone and diamorphine are unavailable. The absence of the analogues alfentanyl and sufentanyl precludes the use of intranasal delivery. In rapid onset BTP, the lipophilic opioids work faster and, in the case of fentanyl analogues, have a short half-life, which is desirable.

\section{Adjuvants}

Most are available and fully funded with the notable exceptions of gabapentin (requires special authority) and ketamine (unfunded outside of hospitals, but available and used).

Unfortunately, access to interventional analgesia (nerve blocks, chordotomy and spinal analgesia [especially intrathecal]) is very limited.

In summary, cancer pain management in New Zealand benefits from comparatively easy access to funded services and most effective pharmaceutical agents, supported by government strategic initiatives. Pain management is based on a holistic model, with attention to nonpharmacological measures. The challenges that remain are demographic variability, ethnocultural specificity and appropriateness, as well as access to newer (and more expensive) pharmaceutical agents in a resource-constrained environment. Cancer pain management is still not a high enough priority across the continuum of care to get the best outcomes for patients.

${ }^{1}$ Hospice South Auckland/Middlemore Hospital; ${ }^{2}$ Mercy Hospice, Auckland, New Zealand

\section{REFERENCES}

1. Ministry of Health, 2001, New Zealand Palliative Care Strategy.

2. Saunders C. The symptomatic treatment of incurable disease. Prescr J 1964:4:68-73.

3. Ministry of Health, 2002. He Korowai Oranga: Maori Health Strategy.

4. Brescia FJ, Portenoy RK, Ryan M, et al. Pain, opioid use, and survival in hospitalized patients with advanced cancer. J Clin Oncol 1992:10:149-55.

5. Donnelly S, Walsh D. The symptoms of advanced cancer. Semin Oncol 1995;22(2 Suppl 3):67-72.

6. Tay WK, Shaw RJ, Goh CR. A survey of symptoms in hospice patients in Singapore. Ann Acad Med Singapore 1994;23:191-6.

7. William L, Macleod R. Management of breakthrough pain in patients with cancer. Drugs 2008;68:913-24.

8. Portenoy RK, Payne D, Jacobsen P. Breakthrough pain: Characteristics and impact in patients with cancer pain. Pain 1999;81:129-34.

9. Fortner BV, Okon TA, Portenoy RK. A survey of pain related hospitalizations, emergency department visits, and physician office visits reported by cancer patients with and without a history of breakthrough pain. J Pain 2002;3:38-44.

10. Fortner BV, Demarco G, Irving G, et al. Description and predictors of direct and indirect costs of pain reported by cancer patients. J Pain Symptom Manage 2003;25:9-18.

11. Portenoy RK. Treatment of temporal variations in chronic cancer pain. Semin Oncol 1997;24(5 Suppl 16):S16-7-12.

\section{Cancer pain: Progress and ongoing issues in Saudi Arabia}

\author{
Mohammad Zafir Al-Shahri MD
}

\section{Cancer in Saudi Arabia}

The tertiary cancer care facilities are localized in a few major cities of Saudi Arabia (SA), which has a total population of 24 million, $73 \%$ of which is Saudi National (1). Approximately 8000 new cancer cases are reported annually in SA, with probable under-reporting (2). The crude incidence rate of cancer in SA is 37.8 of 100,000 and the overall age-standardized incidence is 60.9 of 100,000 . The five most common cancers, in descending order of frequency, are colorectal cancer, nonHodgkin lymphoma, liver cancer, leukemia and prostate cancer in men; and breast cancer, thyroid cancer, colorectal cancer, leukemia and non-Hodgkin lymphoma in women. More than two-thirds of patients are diagnosed with regional or distant disease at presentation $(3,4)$.

\section{Cancer pain management}

Little is known about the prevalence of cancer pain in SA. Given the suboptimal cancer prevention programs and the late presentation of most patients, pain is believed to be a significant problem among cancer patients in SA. Approximately $9 \%$ of patients seen in a pain clinic in a teaching hospital were diagnosed with cancer-related pain (5). The per capita morphine consumption in SA is less than $0.35 \mathrm{mg}$, which is alarmingly low compared with the global mean of approximately $5.6 \mathrm{mg}$ (6). There is some belief that the stringency of national and international regulations is the main obstacle against adequate medical use of opioids in SA (7). However, the fact that morphine and other opioids are listed on the Ministry of Health formulary legally grants hospitals free access to adequate quantities of opioids. Jurisprudence of Islam, the religion of all Saudis, is fairly lenient with respect to medical use of opioids (8). Notwithstanding the multifactorial nature of potential 
obstacles hindering cancer pain control in SA, factors related to health professionals' knowledge and practice seem to play a major role.

\section{Palliative care programs}

King Faisal Specialist Hospital and Research Center (KFSHRC) in Riyadh, SA, started a home palliative care service in 1991. The service soon developed into a comprehensive palliative care program with inpatient, outpatient and home care components (9). A yet-to-be-approved proposal for a national palliative care program was submitted to the Ministry of Health a few years ago, and aimed to establish palliative care services in all regions of the country (10). The first fellowship training program in palliative medicine in Arabic countries was established at KFSHRC in 2000. Graduated fellows were able to start palliative care programs in other health institutions in major cities. Other physicians who gained several years of palliative care experience at KFSHRC have become pioneers in other Arabic countries by establishing palliative care programs in the United Arab Emirates, Qatar and Egypt.

\section{Conclusion}

Supportive health policies, availability of medications and professional education are all prerequisites for optimal cancer pain management. The limited progress made in Saudi palliative care programs over two decades is far from meeting the needs. There is an immediate need for appropriate positioning of palliative care on the national health agenda. At the current stage, one of the priorities is to invest more in palliative care training.

Correspondence: Dr Mohammad Zafir Al-Shahri, PO Box 365636, Riyadh 11393, Saudi Arabia. E-mail malshahri@kfshrc.edu.sa

\section{REFERENCES}

1. Population \& Housing Characteristics in the Kingdom of Saudi Arabia. Demographic Survey 1428 H. (2007). Ministry of Economy $\&$ Planning, Central Department of Statistics \& Information, Kingdom of Saudi Arabia. < http://www.cdsi.gov.sa/pdf/demograph. pdf $>$ (Version current at March 17, 2009).

2. Al-Zahrani A, Baomer A, Al-Hamdan N, Mohamed G. Completeness and validity of cancer registration in a major public referral hospital in Saudi Arabia. Ann Saudi Med 2003;23:6-9.

3. Ministry of Health. Cancer Incidence Report, Saudi Arabia. Riyadh (KSA): Ministry of Health, National Cancer Registry; 2002.

4. Tumor Registry Annual Report. Riyadh (KSA): King Faisal Specialist Hospital and Research Centre; 2006.

5. Kaki AM. Pain clinic experience in a teaching hospital in Western Saudi Arabia. Relationship of patient's age and gender to various types of pain. Saudi Med J 2006;27:1882-6.

6. Opioid Consumption Statistics. Focus on WHO regions - SEARO and WPRO. Madison Pain and Policy Studies Group WHO

Collaborating Center for Policy and Communications in Cancer Care; 2007. <http://www.painpolicy.wisc.edu/publicat/monograp/ aphconf07.pdf> (Version current at March 17, 2009).

7. Nuessle S, Gray A, Lambert G, et al. Pain control with morphine: Evaluation of prescriptions for oral morphine for outpatients at King Faisal Specialist Hospital and Research Centre. Ann Saudi Med 1996;16:371-6.

8. Al-Shahri MZ, Al-Khenaizan A. Palliative care for Muslim patients. J Support Oncol 2005;3:432-6.

9. Gray AJ, Ezzat A, Volker S. Developing palliative care services for terminally ill patients in Saudi Arabia. Ann Saudi Med 1995;15:370-7.

10. Al-Shahri MZ, Brown SM, Bruera ED. Palliative care: Proposal for a national program in Saudi Arabia. Saudi Med J 2004;25:1791-5.

\section{Cancer pain - progress and ongoing issues in Singapore}

\author{
Allyn Hum, Angel Lee, Wu Huei Yaw
}

Cancer is the leading cause of mortality in Singapore, accounting for $26.5 \%$ to $28.5 \%$ of deaths between 2004 and 2007 (1). The Ministry of Health in Singapore responded by setting up comprehensive screening and management strategies for each disease, with development of cancer facilities and services to address the issue. What we have been slower to do is to address needs of patients who fail to respond to treatment and succumb to their disease despite oncological care.

The hospice movement was first started in Singapore in 1985 (2). However, it was only as recently as May 2007 that palliative medicine was finally recognized as a subspecialty, giving it the status and importance needed to promote the agenda of providing excellent symptom care and support to terminally ill patients and their families.

Presently, there are five acute hospital-based palliative care services in Singapore. Patients living with life-limiting illnesses in the community are supported by home-based hospice teams, while four hospice units provide inpatient care for up to 125 patients. Symptom management remains a core component of the work performed across each site of care, particularly the care of patients with cancer pain.

\section{Analgesic availability in Singapore}

Morphine is readily available in Singapore, as are the other analgesics recommended on the World Health Organization pain step ladder, with the exception of hydromorphone, which is not available yet. Per capita global consumption of morphine in Singapore for 2001 was $1.0027 \mathrm{mg}$, against a global mean of $5.73 \mathrm{mg}$ (3). Although cancer pain physicians in Singapore have access to methadone and oxycodone, use is limited to the oral route. This poses practical challenges to continued use in patients who, for a variety of reasons, are no longer able to consume medications orally. When continued administration is required in the parenteral form, rotation to other opioids such as morphine or fentanyl is necessary, possibly disrupting symptom management. Not surprisingly, methadone is underused, despite evidence of benefit in patients suffering from complex neuropathic pain. With only a small population of patients using methadone for the management of difficult pain, it is not economically viable for the local health authority to substantiate the presence of a parenteral counterpart. This has implications not only in the care of patients, but the future training of palliative care physicians in cancer pain.

Ketamine is an alternative option for such patients with difficult pain and is being used with increasing frequency. Adjuvants such as tricyclic antidepressants and gabapentin have proven to be useful allies in neuropathic cancer pain.

\section{Cancer pain collaboration}

Responding to 'pain as a fifth vital sign', formal pain management services led by anesthesia departments were established across all Singapore hospitals in the past five years. Patients with cancer pain are increasingly being referred for interventions such as neurolytic blocks or insertion of intrathecal 
catheters that allow patients to remain at home with the support of the community hospice teams.

Pain is a multidimensional experience. Our ability to help our patients is dependent on our fellow team members who include palliative social workers and nurses. The number of such specialized social workers and nurses is presently still too small to deal with the burgeoning numbers of terminally ill patients and their families, and the risk of burnout is high. Endof-life care has recently gained attention in the popular press in Singapore and efforts are being made to train more people in the field of palliative medicine. In time, a palliative care team in Singapore may also include psychologists, physical therapists and pastoral care workers.

\section{Cancer pain management: The way forward in Singapore}

1. Use of validated measures such as the Edmonton Symptom Assessment System (4) or the Memorial Pain Assessment Card (5) - simple bedside tools that will provide outcome data guiding analgesic treatment and knowledge;

2. Availability of opioids such as methadone (6) and oxycodone in the parenteral form, allowing cancer pain physicians greater flexibility;

3. Acknowledging the complexity of cancer pain and the need for an interdisciplinary approach. Funding needs to increase to support a coordinated service that is able to meet the needs of patients;

4. Continued recruitment and training of more physicians in the management of cancer pain, widening the access of patients to good symptom control; and

5. Reissuing cancer pain guidelines based on local knowledge of analgesic response and availability.

Palliative care in Singapore has grown over the past few years and has benefited recently by public interest in end-oflife care. There are challenges that include the recruitment, education and retention of health care professionals interested in this field. Our clinical management of cancer pain needs to be reviewed and audited, and further research in this field in our part of the world will help inform our practice.

Department of Palliative Medicine, Tan Tock Seng Hospital, Singapore

\section{REFERENCES}

1. Ministry of Health. Health Facts Singapore. <http://www.moh.gov.sg/ corp/publications/statistics $>$.

2. Goh CR. Singapore: Status of cancer pain and palliative care. J Pain Symptom Manage 1996;12:130-2.

3. Opioid Availability in the World. Assuring Availability of Opioid Analgesics for Palliative Care. Geneva, Switzerland, September 2004. $<$ www.medsch.wisc.edu/painpolicy $>$.

4. Nekolaichuk C, Watanabe S, Beaumont C. The Edmonton Symptom Assessment System: A 15-year retrospective review of validation studies (1991-2006). Palliat Med 2008;22:111-22.

5. Fishman B, Pasternak S, Wallenstein SL, Houde RW, Holland JC, Foley KM. The memorial pain assessment card. A valid instrument for the evaluation of cancer pain. Cancer 1987;60:1151-8.

6. Hum A, Fainsinger RL, Bielech M. Subcutaneous methadone: An issue revisited. J Pain Symptom Manage 2007;34:573-5.

\section{Cancer pain - progress and ongoing issues in Thailand}

\author{
Kittiphon Nagaviroj MD, \\ Darin Jaturapatporn MD
}

$\mathrm{T}$ hailand is an independent country that lies in the heart of Southeast Asia. It has approximately 65 million people. Approximately $80 \%$ of the population is ethnically Thai and 95\% of all Thais are Buddhist (1). Based on the national statistical report, malignant neoplasm causes $12.8 \%$ of all deaths and has been the leading cause of deaths since 2004 (1). These data are consistent with the report on the hospital admission rates for people with cancer per 100,000 people, which has increased dramatically from 34.7 in 1994 to 89.4 in 2003 (2). Therefore, cancer is considered to be one of the major health issues in Thailand. The prevalence of cancer pain of those cancer patients admitted was approximately $62 \%$ (3). Nevertheless, cancer pain remains underdetected and undertreated in most cancer patients (4). A study to demonstrate prevalence, characteristics and patterns of management at a teaching hospital revealed that onethird of cancer patients with pain never received any pain control intervention. Approximately one-half of those with persistent pain only received treatment by requesting it and then ended up with only simple analgesics (5).

\section{Challenges in cancer pain management}

There are several challenges in cancer pain management in Thailand. First, there is the lack of education and resources. There is still inadequate undergraduate and postgraduate training in palliative care and pain management. Among 13 medical schools in Thailand, only six have a pain clinic and specialists (6). A study of physicians' basic knowledge and attitudes toward pain medication in cancer patients revealed that $59.3 \%$ of recently graduated physicians and residents did not know how to start pain medication, $59.1 \%$ could not differentiate between physical and psychological dependence and 51.9\% thought that most terminal cancer patients will develop opioid tolerance and addiction. The study suggested that the majority of physicians not only lacked knowledge of cancer pain management but also had negative attitudes toward treatment. In the same study, $86.4 \%$ of physicians identified their need to attend pain management courses (7).

Additionally, compared with other Asian countries, consumption of opioids in Thailand remains extremely low despite increased medical needs. According to the Global Report of Opioid Consumption in 2005 (8), annual consumption of morphine in Thailand is only $0.6219 \mathrm{mg}$ per capita, which ranks it as 70th in global morphine consumption. Due to concern with eradication programs that tackle drug trafficking, Thai government policy limits the quantity and duration of opioid prescriptions. Currently, only $4 \mathrm{~kg}$ of morphine are consumed annually, although the expected amount of morphine to treat cancer pain is $1000 \mathrm{~kg}$. A government hospital can access only $400 \mathrm{~g}$ of morphine, while private hospitals can have $50 \mathrm{~g}$ annually (9). In addition, the national health priorities have not included cancer pain relief. Thai health care society is still 'opiophobic' and reluctant to legitimize opioid analgesics because of the fear of addiction. The rigid drug policy restricts doctors and nurses in their ability to prescribe 
and use opioids, including those with adequate education and training and a willingness to use these drugs appropriately. In addition, access to other treatments such as radiotherapy is not equal in each region. Among 26 radiotherapy facilities in Thailand, 17 of them are in the central part of the country, with the majority in Bangkok. There are shortages of staff, including qualified radiotherapists, physicists and radiographers $(10)$.

Finally, there are also several obstacles for patients and their family to manage cancer pain at home. According to a study on health problems experienced by Thai cancer patients and families, lack of education and fear of the side effects of the medications, especially respiratory depression and addiction, were among their major concerns (11). In the same study, as a result of limited supply of the opioids in primary care facilities, patients reported inconvenience in refilling their prescriptions.

Despite these obstacles, however, some progress has been made. In 1990, the Thai Association for the Study of Pain was established, and has subsequently had a strong influence in pain education and the development of effective pain management strategies. In 1992, the International Association for the Study of Pain, with sponsorship from the World Health Organization and the Ministry of Public Health, conducted a national workshop that acknowledged problems in cancer pain management and promoted the World Health Organization method of controlling cancer pain. Following this, participants issued a consensus recommendation that education and training in cancer pain management was needed, urging a review of the national legislation regarding drug use for medical purposes including specific guidelines on the use of opioids for cancer pain, with urgent consideration for forming a national policy for cancer pain management. In 2004, with the collaboration of the National Cancer Institute, the Thai Food and Drug Administration and the Thai Association for the Study of Pain, clinical practice guidelines for cancer pain management were successfully developed.

\section{CONCLUSION AND RECOMMENDATIONS}

Issues surrounding cancer pain management in Thailand are multidimensional, involving education for health care professionals and a rigid national drug policy, as well as negative public attitudes toward pain medications. These problems emphasize the importance of establishing more intensive educational programs, reviewing national drug legislation for medical purposes, and raising public awareness around palliative care and cancer pain management.

Department of Family Medicine, Ramathibodi Hospital, Mahidol University. Correspondence: Dr Kittiphon Nagaviroj, Department of Family Medicine, Ramathibodi Hospital, 207 Rama VI Street, Rajthevi, Bangkok, Thailand, 10400. Telephone 662-201-1486, e-mail raknv@mahidol.ac.th

\section{REFERENCES}

1. The Key Statistics of Thailand 2007. Bangkok: National Statistical Office of Thailand, Statistical Forecasting Bureau.

2. Wibulpolprasert S. Thailand health profiles 2001-2004: Printing Press, Express Transportation Organization; 2005.

3. Vatanasapt VSM, Tailert J, Vatanasaksiri D, Sriamporn S, Boonrodchu D. Incidence of cancer pain in Khon Kaen, Thailand. Thai Cancer J 1992:64-70.
4. Petpichetchian W. The cancer pain experience in Thai patients: Meaning of pain, control over pain, pain coping and pain outcome. [Unpublished doctoral thesis]. Detroit: Wayne State University, 2001.

5. Vatanasapt P, Lertsinudom S, Sookprasert A, et al. Prevalence and management of cancer pain in Srinagarind Hospital, Khon Kaen, Thailand. J Med Assoc Thai 2008;91:1873-7.

6. Bureau of Medical Technical Department DoMS, Ministry of Public Health. CPG: Management of Cancer Pain, 1st edn. Bangkok: The Agricultural Co-operative Federation of Thailand Ltd Press, 2004.

7. Chinda M, Hathirat S, Waikakul W, Ittichaikulthol W. Physician's basic knowledge and attitudes toward pain medication in cancer patients. WoncaEurope 2006; Italy, 2005.

8. Group PPS. Opioid Consumption Statistics Focus on WHO Regions. 7th Asia Pacific Hospice Conference; Manila, Philippines, 2007.

9. Thai Controlled Substance Legislation: Narcotics Control Division, Food and Drug administration of Thailand; 2003. < http://elib.fda. moph.go.th>.

10. Petsuksiri YCJ. Current status of radiation therapy in Thailand. Radiat Med 2004;22:6-7.

11. Nagaviroj K. How Multidisciplinary Palliative Home Care Team manages health problems in advanced cancer patients. Asia-Pacific WONCA conference; Bangkok, Thailand, 2006.

\section{Cancer pain - progress and ongoing issues in the United Kingdom}

\author{
Marie Fallon
}

In the United Kingdom (UK), there is a largely politically 1 driven belief that cancer pain has been managed effectively. When planning research agendas, it is usually stated that 'cancer pain has been dealt with'! The evidence, however, points to another picture - the Scottish National Cancer Pain Audit shows that at least $50 \%$ of all patients with active advanced cancer have at least moderate pain (1). Similar patterns of cancer pain control are repeated in several areas of the UK.

For those who identify that cancer pain remains problematic, some platforms have been developed over the past five years:

1. Basic science collaborations;

2. Facilitation of clinical collaborations;

3. Funding opportunities; and

4. Government policy documents.

\section{Basic science collaborations}

Key basic scientists, such as Professor Anthony Dickenson, have not only shared ideas with palliative medicine and pain clinicians but have trained clinician scientists in palliative medicine which, in turn, has informed and evolved the understanding of cancer pain research at the bedside.

Bench-to-bedside translation has already been achieved in some collaborations and is likely to evolve further. The area of metastatic bone pain is still the best example, and new insights are developing (2). The gabapentin work by Dickenson's group has already been translated into a multicentre clinical trial (funded by Cancer Research UK) using pregabalin as an adjuvant treatment for cancer-induced bone pain.

\section{Facilitation of clinical collaborations}

It is indisputable that the idea of setting up and funding the meetings of a National Cancer Research Institute group dedicated to developing palliative care studies has been instrumental in moving cancer pain research (along with other palliative 
care research) to a different level. Previously, the vast majority of multicentre studies were pharmaceutical industry drug trials. This has evolved to investigator-led multicentre studies using a variety of methodologies, ranging from standard double-blind randomized placebo-controlled trials of adjuvant treatments for bone and neuropathic pain, to head-to-head studies and cluster methodology. For the first time, we have 18 cancer centres in the UK collaborating on a cancer pain management cluster-randomized trial - "Does the institutionalisation of pain assessment using the EPAT package reduce pain in cancer unit inpatients more than usual care; a cluster randomised trial" (3). This collaboration, while answering an important very practical question, should be a platform for further collaborations.

\section{Funding opportunities}

A review by the National Cancer Research Network established that only $3 \%$ of all research funding went to any form of palliative care research. An explicit aim to increase this percentage was expressed at the same time as setting up the National Cancer Research Institute group mentioned above (4). On a practical level, the main funding bodies combined 'ring-fenced' money to support two 'Research Collaboratives' in Supportive and Palliative Care, with the aim of increasing research capacity. A benefit of the collaborative approach was to engage with experienced researchers from other areas who had expertise that could be transferred to palliative care. Cancer pain research benefited from this by exposure to different methodologies and senior statistician expertise.

\section{Government policy documents}

Key policy documents have been increasingly making clear statements relating to the fact that we know, in detail, most of the problems our patients face and, in fact, that this is the 'easy' part of research. A call for solutions to the problems rather than just more information on the problems is overdue.

The result of the recent End of Life Care Strategy, combined with a platform for collaborations and multicentre research - some of which are informed by basic science - has resulted in cancer pain moving from the 'Cinderella spot' of 'having been dealt with' (5). The result is confidence that we can find better solutions to old problems and the real potential of entirely new treatments.

\section{REFERENCES}

1. Welsh J, Fallon M, Stroner P, et al. Prevalence of pain in patients with active cancer in Scotland: A National Cross-sectional Survey. IASP 1999, Abstracts of the 9th World Congress on Pain. Abstract 220, 568.

2. Donovan-Rodriguez T, Dickenson AH, Urch CE. Gabapentin normalizes spinal neuronal responses that correlate with behavior in a rat model of cancer-induced bone pain. Anesthesiology 2005;102:132-40.

3. Fallon MT, Clausen E, Walley J, et al. Can the institutionalisation of cancer pain assessment as a 5 th vital sign improve cancer pain control in the acute setting? Palliat Med 2006;20:231-2. (Abst)

4. NCRI Strategic Analysis. An Overview of Cancer Research in the UK directly funded by the NCRI Partner Organisations. 2002; 6-7.

5. Department of Health. End of Life Care Strategy, July 2008. $<$ http://www.dh.gov.uk/en/Publicationsandstatistics/Publications/ PublicationsPolicyAndGuidance/DH_086277>.

\section{Cancer pain - progress and ongoing issues in the United States}

\author{
Shalini Dalal MD, Eduardo Bruera MD
}

U nrelieved pain affects the lives of millions of cancer patients worldwide, and is associated with unnecessary suffering and huge societal costs. Despite extensive efforts and advances in therapeutic options, education and public health policy, the literature continues to report high prevalence and undertreatment of cancer pain $(1,2)$, with figures that have been essentially unchanged for decades.

Fortunately, the past decades have witnessed significant advances in basic pain research $(3,4)$. In cancer, the development of unique tumour pain animal models have been crucial in providing valuable insight into how the tumour, or the reactions it induces in the host, leads to pain $(5,6)$. A major concept that has collectively emerged is that a combination of events in the peripheral and central nervous systems contribute to chronic pain development, including inflammation, neuronal sensitization, synaptic remodelling, glial cell activation and expression of pronociceptive genes. These advances bring us closer in our search for objective biomarkers of cancer pain (eg, genes involved in plasticity; imaging techniques) and in the development of a new series of molecular mechanisticbased therapies that stand poised to upend the current paradigm of cancer pain management.

That said, the new era in pain research, impressive though it is, has so far had limited impact in the clinical arena of cancer pain. Current pharmacological treatments remain largely empirical rather than mechanistic. Variations in individual responses to drugs remain poorly understood, leading to empirical rotation of commonly used drugs, and not much more than that. In the past decade, there have been very few major clinical additions to the traditional pharmacopeia of opioids, nonsteroidal anti-inflammatory drugs and adjuvants. Progress has been limited to better use of existing modalities, and most so-called 'new drugs' are either newer delivery approaches, or slow- and fast-release formulations of existing agents. For example, of the 21 phase III pharmacological trials currently underway for treatment of cancer pain, $86 \%$ are of existing agents, such as opioids (12 trials, nine of fentanyl) and others including ketamine, amitriptyline, dexamethasone, acetaminophen, pregabalin and duloxetine; only three trials are investigating new agents (tetrodotoxin and xaliproden) (7). However, many potentially attractive novel compounds are being studied in chronic pain syndromes outside the realm of cancer research. There is some reluctance on the part of the pharmaceutical industry to invest in cancer pain. There are also challenges to conducting such trials, including the heterogeneity of cancer pain, the difficulty in accruing symptomatic patients, the ethical problems associated with placebo controls in patients with pain, the high dropout rates and the choice of appropriate assessment measures and end points.

Both management and research in cancer pain has been greatly hampered by existing methods of pain assessment, relying heavily on simplistic self-report based instruments, while many of the characteristics that have potential to influence success in pain management are seldom assessed. In reality, 
chronic pain in cancer patients is a multifaceted, complex syndrome involving biological, psychological and social contributors and consequences. Various factors influence the production, perception and expression of pain, including tumour, treatment and individual characteristics (eg, genetics, emotional/cognitive status, sociodemographics and history of addiction). We need to be cautious in using single numerical pain ratings alone for treatment or quality assurance purposes because scores can be influenced by the presence of chemical coping, delirium and other factors. Use of a standardized systematic approach in assessment of these various domains has the potential to increase treatment efficiency by tailoring treatments that are specific to individual patient needs. Furthermore, this approach will allow for the development of a universally accepted classification system with subgrouping of patients that can provide a basis for specific treatment and resource allocation, and prediction of treatment outcomes. The few classification systems developed for cancer pain (8) were rarely used and, in recent years, there has been a renewed vigor in further developing this field (9). Another limitation is that pain in cancer patients is usually assessed in isolation from all other symptoms that may be present, such as anxiety, nausea, delirium and sedation. The challenge, therefore, is to also include multiple symptom assessments such as the Edmonton Symptom Assessment System (ESAS) (10). Several efforts are being made on this front. For instance, the province of Ontario has set forth a goal to have $80 \%$ of patients undergo ESAS in all cancer centres, not just in specialty palliative care clinics (11).

There have been extraordinary advances in multiple areas of pain research and there is increasing hope that these will lead to the clinical development of more effective treatment options for cancer pain. It is crucial that, in the midst of this paradigm shift, we go beyond current minimalist approaches in our assessment of cancer pain. When considered with the many efforts currently underway, including those under the auspices of the International Association for the Study of Pain's Global Year Against Cancer Pain, there is a realistic and powerful opportunity to bring help and hope to people contending with cancer pain.

Eduardo Bruera is supported in part by National Institutes of Health grant numbers: RO1NR010162-01A1, RO1CA122292-01 and RO1CA124481-01

Department of Palliative Care and Rehabilitation Medicine, University of Texas MD Anderson Cancer Center, Houston, Texas, USA. Correspondence: Dr Shalini Dalal, Department of Palliative Care and Rehabilitation Medicine - Unit 008, University of Texas MD Anderson Cancer Center, Houston, Texas 77030, USA. Telephone 713-792-6085, fax 713-792-6092, e-mailsdalal@mdanderson.org

\section{REFERENCES}

1. van den Beuken-van Everdingen MH, de Rijke JM, Kessels AG, Schouten HC, van Kleef M, Patijn J. Prevalence of pain in patients with cancer: A systematic review of the past 40 years. Ann Oncol 2007;18:1437-49.

2. Deandrea S, Montanari M, Moja L, Apolone G. Prevalence of undertreatment in cancer pain. A review of published literature. Ann Oncol 2008;19:1985-91.

3. Milligan ED, Watkins LR. Pathological and protective roles of glia in chronic pain. Nat Rev Neurosci 2009;10:23-36.

4. Ji RR, Woolf CJ. Neuronal plasticity and signal transduction in nociceptive neurons: Implications for the initiation and maintenance of pathological pain. Neurobiol Dis 2001;8:1-10.

5. Pacharinsak C, Beitz A. Animal models of cancer pain. Comp Med 2008;58:220-33.

6. Mantyh PW, Clohisy DR, Koltzenburg M, Hunt SP. Molecular mechanisms of cancer pain. Nat Rev Cancer 2002;2:201-9.

7. <www.clinicaltrials.gov>.

8. Bruera E, MacMillan K, Hanson J, MacDonald RN. The Edmonton staging system for cancer pain: Preliminary report. Pain 1989;37:203-9.

9. Fainsinger RL, Nekolaichuk CL. A 'TNM' classification system for cancer pain: The Edmonton Classification System for Cancer Pain (ECS-CP). Support Care Cancer 2008;16:547-55.

10. Bruera E, Kuehn N, Miller MJ, Selmser P, Macmillan K. The Edmonton Symptom Assessment System (ESAS): A simple method for the assessment of palliative care patients. J Palliat Care 1991;7:6-9.

11. Dudgeon DJ, Knott C, Eichholz M, et al. Palliative Care Integration Project (PCIP) quality improvement strategy evaluation. J Pain Symptom Manage 2008;35:573-82. 


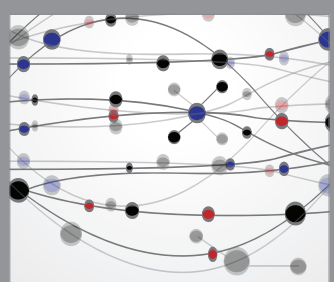

The Scientific World Journal
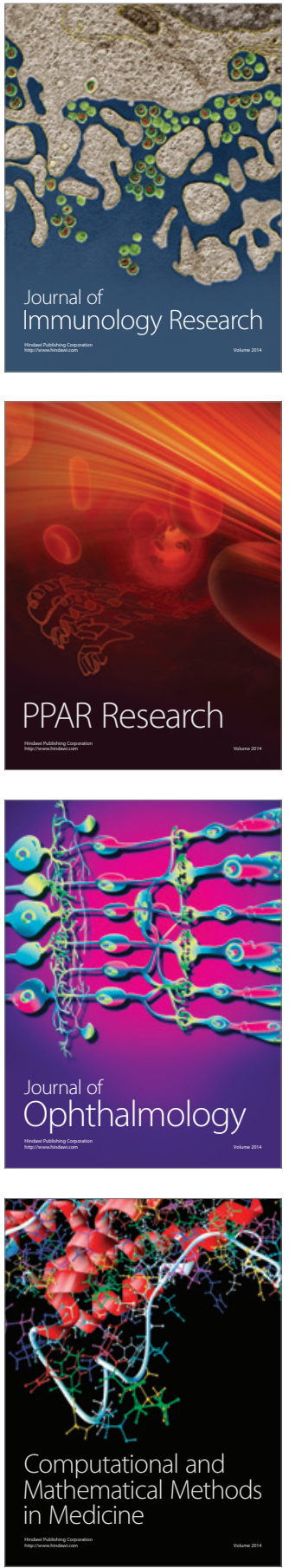

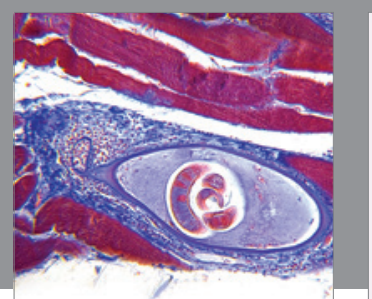

Gastroenterology Research and Practice

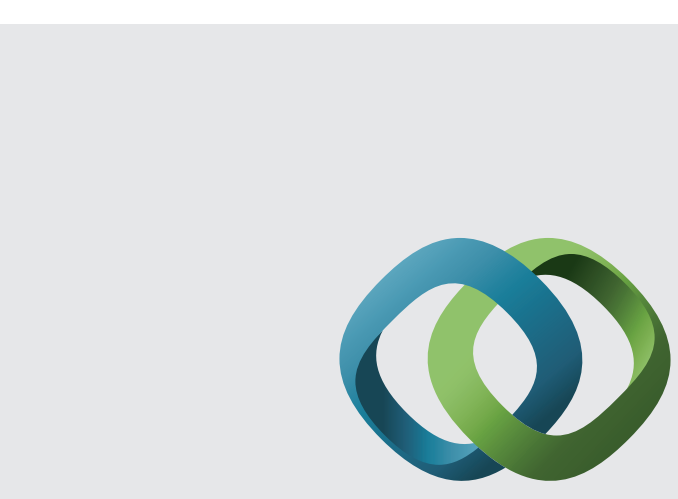

\section{Hindawi}

Submit your manuscripts at

http://www.hindawi.com
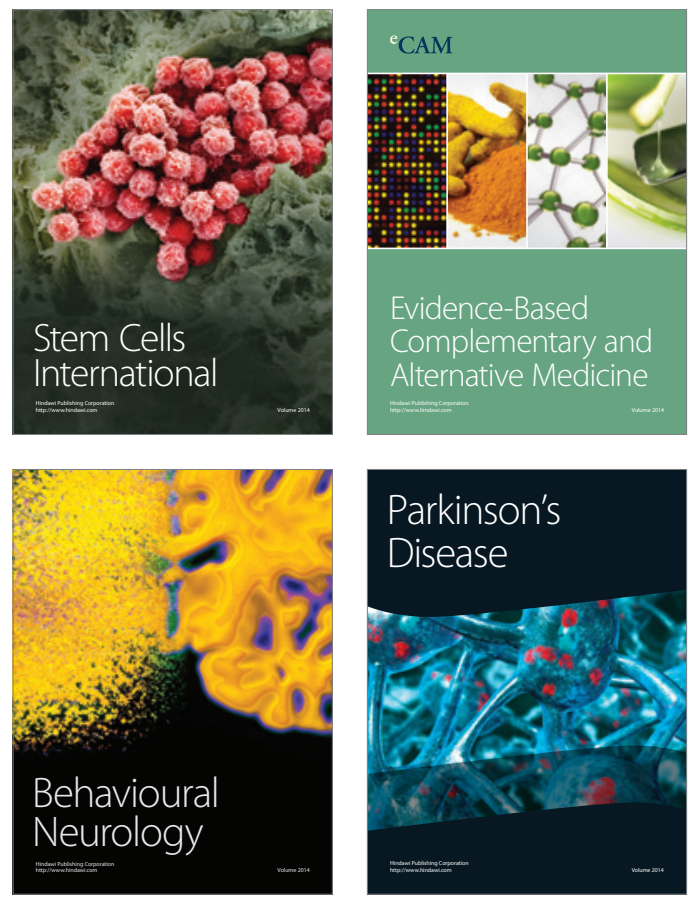
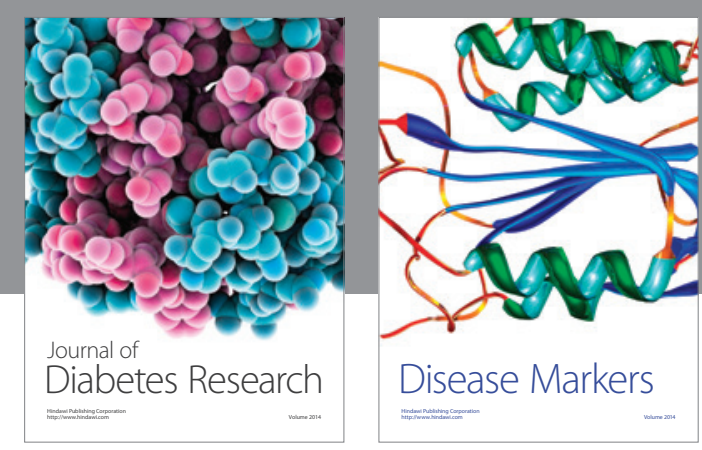

Disease Markers
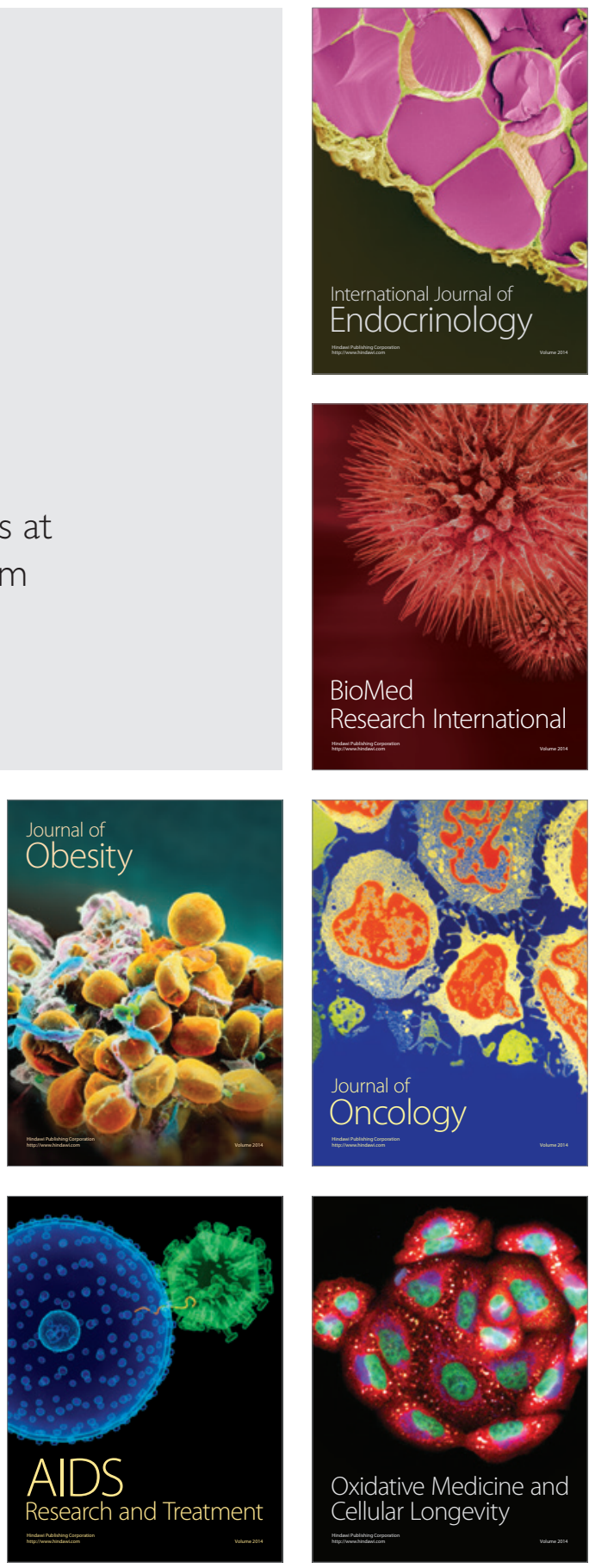